\title{
LIFE IN A BHUMIJ VILLAGE DURING LOCKDOWN: AN EXPLORATIVE STUDY
}

\author{
Dr. Nizamuddin Ahmed ${ }^{1}$ \\ ${ }^{1}$ Assistant Professor, Department of Education, Haldia Govt. College, Purba Medinipur, West \\ Bengal, India \\ Biswajit Goswami ${ }^{2}$ \\ ${ }^{2}$ Ph.D. Research Scholar, Swami Vivekananda Centre for Multidisciplinary Research in \\ Educational Studies, University of Calcutta recognized Research Centre under Ramakrishna \\ Mission Sikshanamandira, Belur Math, Howrah, West Bengal, India \\ Swami Tattwasarananda ${ }^{3}$ \\ ${ }^{3}$ Professor, Ramakrishna Mission Sikshanamandira, Belur Math, Howrah, West Bengal, India
}

Article DOI: https://doi.org/10.36713/epra4902

\begin{abstract}
Since midnight of March 25, 2020, India's 1.3 billion people had gone under total lockdown to combat the spread of the novel coronavirus (COVID-19) pandemic and this prolonged countrywide lockdown has a serious impact on the life of the Indian tribes like their income, occupation, social life, personal life etc., as they are the most vulnerable and poor marginalized people of India, having neglected through the ages in every aspect of their life and livelihood. Bhumij tribe is one of them. They mainly reside in the Indian state of Odisha, Jharkhand, and West Bengal. Lutia is a typical Bhumij concentrated village in the area of Simlabandh under Hirbandh community development block of Khatra sub-division in the district of Bankura of the Indian state of West Bengal. By maintaining proper social distance and wearing face mask we have taken in-depth interview of 25 villagers of different age group and gender belong to Bhumij tribal community in this village on the various aspects of their day to day life, their education, their health awareness especially about the awareness regarding COVID19, their culture, religious and supernatural beliefs, etc. by adopting purposive sampling technique method along with tried to know their opinion and views regarding the impact of countrywide lockdown to their daily life. Therefore, in this paper, an attempt has been made to explore their life during the lockdown.
\end{abstract}

KEY WORDS: Bhumij tribe, Life of Bhumij, Lockdown, Covid-19, Lutia Village of Bankura district.

\section{INTRODUCTION}

Prime Minister of India had announced complete lockdown throughout the country from the midnight of $25^{\text {th }}$ March 2020 in his address to the Nation through television on $24^{\text {th }}$ March 2020. Since midnight of March 25, 2020, India's 1.3 billion people had gone under total lockdown for 21 days to combat the spread of the novel coronavirus (COVID19) pandemic. Then after phase by phase, this countrywide complete lockdown had extended up to May 31, 2020. This prolonged 68 days countrywide lockdown has a serious impact on every section of life of the Indian like their income, occupation, social life, personal life etc. This lockdown has severely affected the most vulnerable and the poor marginalized people of India. Indian tribes through the ages are neglected in every aspect of their lives and livelihood. This lockdown has seriously affected 


\section{EPRA International Journal of Research and Development (IJRD)}

their life and livelihood as they are the most vulnerable neglected marginalized community among the Indians. There are about 645 distinct tribes in India with their total population of 10.43 crore as per the Census 2011 which accounts for $8.6 \%$ of the total population of the country. Bhumij tribe are one of them and they mainly reside in the Indian state of Odisha, Jharkhand, and West Bengal. Etymologically the term 'Bhumij' means one who is born from the soil. The Bhumij as being the earlier settlers were in possession of the land. They are settled, agriculturists. The tribe is mainly divided into four endogamous groups like Tamudia or Tamaria Bhumij, Haldipokhoria Bhumij, Teli Bhumij and Desi or Dehuri Bhumij. Each section of these groups consists of a number of exogamous totemic subgroups called killi. The Bhumij family is nuclear, patrilineal and patripotestal. Famous anthropologists like E. T. Dalton and H. M. Risley identified the Bhumij as a Hinduised branch of Mundas who entirely had been transformed into the Hindu caste in the eastern fringe of Ayodhya Range. Risley observed, Bhumij are the pure Dravidian race have lost their original language now speak only in Bengali; they worship Hindu god and goddess in addition to their own (the tendency being to relegate the tribal gods to the women) and more advanced among them employ Brahmans as family priests. They still retain a set of totemic exogamous subdivision closely resembling those of the Mundas and Santals. As a result, there was an impact of both tribal Mundari socio-cultural traits and Hindu traits on the Bhumij people. Bhumij is known by different names to Mundari linguistic family within the 'kherwari' group which an important branch of under the great Austro-Asiatic family. In the Indian state of West Bengal Bhumij tribe are mainly concentrated in the districts of Paschim Medinipur, Jhargram, Purulia, Bankura, South24 Parganas and North 24 Parganas. Bhumijs are the $4^{\text {th }}$ largest tribal community in West Bengal after the Santal, Oraon and Munda. As per the Census 2001, their total population was 336,436 which were the $7.6 \%$ of the total Scheduled Tribe (ST) population in West Bengal. In this paper, an attempt has been made to discuss the life of the Bhumij during lockdown due to combat of the spread of novel coronavirus (COVID19) pandemic of a village, Lutia. Lutia is a typical Bhumij concentrated village in the area of Simlabandh under Hirbandh community development block of Khatra sub-division in the district of Bankura of the Indian state of West Bengal.

\subsection{OBJECTIVES OF THE STUDY}

The objectives of this explorative study on Bhumij tribal community of a village, Lutia of Bankura district in the Indian state of West Bengal are given below:
- To know the life of Bhumij of a village namely Lutia of Bankura district in West Bengal.

- To know the impact of Lockdown due to COVID-19 in their day to day life.

\section{AN OVERVIEW OF THE VILLAGE}

The village Lutia is a typical Indian tribal village of Bhumij tribal community. The village situated beside the river of Kangsabati. This Bhumij concentrated village, Lutia of Moshiara grampanchayat in the area of Simlabandh post office under Hirbandh community development block and Hirbandh police station of Khatra sub-division in the district of Bankura of the Indian state of West Bengal are geographically located at $23.05^{\circ} \mathrm{N}$ latitude and $86.81^{\circ} \mathrm{E}$ longitude. The mouza of Lutia village is also with the name of Lutia with J.L. No.-47. This village is situated approximately $12.4 \mathrm{~km}$ away from its block headquarter Hirbandh. Bankura is the districts headquarter of Lutia village. The total geographical area of this village is 303.71 hectares. According to census 2011, Lutia has a total population of 108 peoples. There are about 19 houses in Lutia village. Nearby some villages of Lutia are Bamni, Kundurka, Paira, Simlabandh, Bhedua and Manora. The nearest town of this village is Khatra with distance from this village about $22 \mathrm{~km}$. The villagers go to this town by bus mainly as this village is not connected with railway transportation. When we went to this village we saw that village road has been constructed into the concrete. By interviewing with a senior villager, Kanad Ranjan Kotal (name changed due to protect his privacy) of 75 years old of this village we know that their ancestors displaced due to struggle in their community people from the nearest Purulia district area had come to this area before 150 years ago and later on they gradually developed the present village area by cutting the jungle.

\section{METHODOLOGY OF THE STUDY}

In this pandemic situation it is not an easy task to carry out any research especially in the field of social sciences. As the tribal people generally are isolated from their outer world in so many reasons and as well as due to our special interest to know about various tribal community not only in India but also in abroad, we have decided to know at least one tribal village population's life in this lockdown period. Before the field survey to this tribal village we have talked to the local administration and let them know our desire of field survey, then also we have gathered various information about this village and surrounding area along with total Hirbandh block situation regarding COVID-19 pandemic from the 


\section{EPRA International Journal of Research and Development (IJRD)}

different websites of the government of West Bengal. Every statistics showed that the entire Hirbandh block area was COVID-19 free area along with that particular Bhumij concentrated tribal village i.e. Lutia village. So then we decided to take a visit to Lutia village. We went to this village on June 27 , 2020; June 28, 2020, and on June 29, 2020, i.e. during the unlock phase 1.0 period and we have spent the whole day to this village by maintaining every norms and regulation of World Health Organization (WHO), Indian Council of Medical Research (ICMR), and as well as the various directives measure of Government of West Bengal and local government regarding COVID-19 pandemic. We have taken enough dry food, drinking water, hand sanitizer and face masks with us before every day to enter the village and always wore face mask properly and also used hand gloves during the field visit. When we talked to the villagers, we always maintained the proper social distance at least more than 6 feet. By maintaining proper social distance and wearing face mask we have taken indepth interview of 25 villagers of different age group and gender belong to Bhumij tribal community on the various aspects of their day to day life, their education, their health awareness especially about the awareness regarding COVID-19, their culture, religious and supernatural beliefs, etc. by adopting purposive sampling technique method along with tried to know their opinion and views regarding the impact of countrywide lockdown to their daily life. In this field visit, we have also emphasised upon the techniques of observation for knowing their life in their day to day activities. We have taken enough field notes about their life especially in this pandemic situation during our field visit and taken some photographs of them in various moments for documentation their life and livelihood with due verbal permission from them.

\section{FINDINGS AND DISCUSSIONS}

The details findings, as well as discussions of this explorative study in a Bhumij tribal village, Lutia of Bankura district in the Indian state of West Bengal, have described in the following subsections:

4.1. Demography: As per the Population Census 2011, a total of 19 families are residing in the village Lutia. The total population of Lutia is 108 out of which 57 are males and 51 are females thus the Average Sex Ratio of Lutia is 895 . The population of Children of age group 0-6 years in Lutia village is 8 which are $7 \%$ of the total population. There are 6 male children and 2 female children between the age group 0-6 years. Thus as per the Census 2011, the Child Sex Ratio of Lutia is 333 which is less than
Average Sex Ratio (895) of Lutia village. Both the sex ratio of Bhumij tribe at Lutia village is far below from the national average. The child sex ratio of Bhumij tribe at Lutia village is in the danger position; it is a serious matter to be concerned if they will be survived in future.

As per the information shared by the villagers of this Bhumij concentrated village, it has seen that at present total 21 families are residing in the village, Lutia. The total population of Lutia is 128 out of which 72 are males and 56 are females thus the Average Sex Ratio of Lutia is 777. At present, the population of Children of age group 0-6 years in Lutia village is 11 which are $8.5 \%$ of the total population. There are 8 male children and 3 female children between the age group 0-6 years. Thus at present, the Child Sex Ratio of Lutia is 375 . Thus at present, a very slight improve has seen in child sex ratio at Lutia village concerning census 2011, but it has remained in very danger and the average sex ratio of this village has declined by 118 points with respect to the population census 2011 which also the very alarming situation for this tribal community at this village. It is also informed to us by the villagers that most of the Bhumij people of this village i.e. about $70 \%$ have no valid scheduled tribe (ST) certificate and about $50 \%$ have no bank account in their name.

4.2. House Pattern: All the houses of this Bhumij village are kutcha and with the typical traditional tribal structure of the house. The wall of those houses is made with mud and roof is made with corrugated tin, asbestos, mud-tiles, etc. Most of the houses have only one room at the centre of the house and besides the four sides are like to see veranda. Bhumij peoples generally sleep in this veranda in the night and during the summer season they like to sleep under the sky. We did not see any kitchen room in their houses. We also did not see sanitary toilet facility to any house of this village. Drinking water facilities are well in this village and this facility has done by the local gram-panchayat authority by providing running water through pipe-line to this village. We saw that females have cooked in front of their house in mud made oven with firewood during our field visit. One housewife, Rani Kotal (name changed due to protect her privacy) of 26 years old informed us that no families in this village use LPG gas for their cooking. Electricity facilities have found in every house in this village. In this context, Sadhan Sing Sardar (name changed 


\section{EPRA International Journal of Research and Development (IJRD)

due to protect his privacy), the only graduate unmarried person of 43 years old said to us that they do not get any direct subsidy in their electric bill though they all belong to below poverty line.

4.3. Family Pattern: As already stated, among the 21 families in this village, most of the small-sized family ( 3 members or less) have seen. The number of such families is 14 $(66.66 \%)$ and the rest of the families i.e. 7 $(33.33 \%)$ is a medium-sized family having 46 members correspond to the simple family consisting of father, mother and their dependent children.

\subsection{Using of Modern Electronic} Gadgets and Internet: In every family there is at least one normal mobile and we have seen only 4 young Bhumij people with a smartphone in their hand during our 3 days field visit at this village. Among the 21 families, only $2(9.52 \%)$ families have a television with direct to home (DTH) connection. No one in this village uses the internet in their day to day life except only those 4 young people who frequently use their mobile internet to access mainly various social media like Facebook, WhatsApp, YouTube, etc.

4.5. Education: As per the Census 2011, the literacy rate of Lutia is $62 \%$. So it has seen that Lutia village has a lower literacy rate compared to $62.1 \%$ of Bankura district. The male literacy rate is $78.43 \%$ and the female literacy rate is $44.9 \%$ in Lutia village. Sadhan Sing Sardar (name changed due to protect his privacy), the only graduate unmarried person of 43 years old said to us that there is no Primary School in their village area. The nearest primary school from this village is about $2 \mathrm{~km}$ away and the connective road from this village to that school is throughout a jungle with fear of Hyenas. Primary schoolgoing children from this village frequently off their school due to the fear of Hyenas. He also said that most of the literate person's education levels of this village are up to primary level i.e. below or class IV standard education and he also added in this context that at present younger generation from this village quit their education after class VI or VII due to poor income of their family and also due to the no guaranty of a job after completion of education. Only two high school girl students from this village have got Kanyashree (Kanyashree Prakalpa, an initiative made by the Government of West Bengal since 2012, seeks to improve the status and wellbeing of girls, specifically those from socio-economically disadvantaged families through Cash Transfers to their bank account) from their school. Sunil Kotal (name changed due to protect his privacy), father of a Class VII student, of 44 years old said to us that his son was reading in Class VII by staying at Moshiara High School hostel, which was dedicated to the schedule tribes (ST) students only but in 2019 school authority suddenly stooped the hostel, as a result, his son left that school during his class VII studies and his son now helps him in his work. He very sadly shared his experience and blamed the school authority for their sudden stopping of the hostel, which was the main cause of his son's drop-out from school. Rupai Sing Sardar (name changed due to protect his privacy), father of a Class VI student, of 41 years old said to us that his son was reading in Class VI by staying at Gopalpur High School hostel, which was dedicated to the schedule tribes (ST) students only but from the month of December, 2019 school authority suddenly stooped the hostel, as a result, his son left that school during his class VI studies and his son now helps him in his work. He very sadly shared his bitter experience and blamed the school authority for their sudden stopping of the hostel, which was the main cause of his son's drop-out from school. In addition to that, he also informed that Deulgaria High School, one of the nearby schools from this village area, also stopped their hostel facility for the tribal students since 2019. As tribal people prefer residential school, so local school authority and as well as government administrations and officials should always try to run tribal hostels smoothly otherwise tribal students deprived so much from getting their education, which is the main key elements to uplift them in mainstreaming society and as well as the wellbeing of them. When we asked a senior villager of this village, Nirapada Sing Sardar (name changed due to protect his privacy), aged about 50 years about the effect of lockdown to their community's students in their village, he replied that students are now engaged to their family work and almost all are detached from their studies as schools remained closed since last 3.5 months and also he shared his wordiness in this context that so many students will not go back to their school when it will reopen as they are long time detached from their studies. So the scenario in the field of secondary education and higher education of this Bhumij people dominated village is alarmingly very poor. Local 


\section{EPRA International Journal of Research and Development (IJRD)

administrations, as well as government authorities, should focus this tribal community's needs and demands as their children will get proper secondary education as well as higher education.

4.6. Health Awareness With Special Reference To COVID-19: Sadhan Sing Sardar (name changed due to protect his privacy), the only graduate unmarried person of this village of 43 years old said to us that people from their community are now a day's conscious about their health. Women from this village regularly have taken consultation from doctors of the primary health centre and block health centre during their pregnancy period and admitted to hospitals for delivery of the baby. They regularly have taken their children immunization from the primary health centre and for any illness, they go to doctors besides that he also added still there is a practice to go to exorcists (Ojha) mainly for snake bites, jaundice, skin diseases, Scorpion bites, etc. He also said to us that, ASHA workers (One of the key components of the National Rural Health Mission is creating a band of female health volunteers since April, 2005, appropriately named "Accredited Social Health Activist" (ASHA) in each village within the identified States. These ASHAs would act as a 'bridge' between the rural people and health service outlets and would play a central role, in achieving national health and population policy goals.) are very active in their village and they regularly monitor every household person regarding their health matter.

We have asked many villagers of this village that do they know about the recent pandemic of COVID-19 and its preventive measures, in reply to that all said to us that they have heard about this disease and aware about its preventive measures from the ASHA workers, though during our field visit we have seen that people did not use face-mask or face-mask like any cloth in outside of their home and did not maintain proper social distance in public places. Rani Kotal (name changed due to protect her privacy) of 26 years old housewife said to us that they used soap and detergent in their daily life but she did not know about hand-sanitizer. During our field visit once morning we observed that younger Bhumij people cleaned their teeth by brush with toothpaste while older Bhumij people used branch of Babool (Acacia nilotica) tree for cleaning their teeth. Maheswar Sing Sardar (name changed due to protect his privacy), aged about 52 years said to us that very recently 15 migrant workers having an original resident of their village came back from their workplace of different Indian states like Maharashtra, Gujarat, Kerala, and Odisha and they all have kept themselves in homequarantine for 14 days and ASHA workers have regularly monitored them.

4.7. Occupation: Most of the Bhumij people in this village have engaged in fishing from the Kangsabat River and they sell fishes in their nearby market. Some are engaged in MGNREGA (Mahatma Gandhi National Rural Employment Guarantee Act) work which is popularly known as 100 days work. In this context, we have informed by the villagers that only about $40 \%$ have a job card in this MGNREGA scheme. Bhumij people in this village have no land in their name except their house, though very few Bhumij people do cultivate boro paddy (boro: rice sown in winter and harvested in summer season is called boro rice) in the bank of the river Kangsabati once in a year. Most females along with some male of this Bhumij dominated village earn money by doing work in the field of animal husbandries like cattle, sheep, hen, goat, goose, etc.

4.8. Marriage: The Bhumij in this village belong to different clans, such as Jag Rishi, Tesa and Path Hembram. Marriage within the same gotra (clan or lineage) is forbidden. The average age of marriage of male and female Bhumij people in this village are 16-21 and 14-16 years respectively as per the information shared by most of the villagers of this village during our field survey. So it has seen that early marriage is very much prominent among the Bhumij people in this village.

4.9. Religious Beliefs and Rituals: The Bhumij in this village are traditional Hindus in religious belief. They worship Hindu deities like kali and mansha by inviting Hindu brahmins to act as priests. They still preserve some of the customs of their ancient religion. Some of their primaeval deities are Deota, Daram Deota, Singbonga and Jahubora. Their traditional religious place in this village is called as Kadamtala, where they worship their primaeval deities by the priests from their community people who are called lavas by sacrificing different animals like goat, hen, etc. to their deities.

4.10. Festivals: Some of their traditional festivals are Salui Hula, Bandana, Tushu and Karam. Among these festivals, Salui Hula (a festival of Bhumij people, when Sal [Shorea 


\section{EPRA International Journal of Research and Development (IJRD)

robusta] tree evolves its new leaf) is celebrated very gorgeously by the Bhumij people in this village. During every festival of them, Bhumij male drinks haria (a special country liquor made by fermentation of rice).

4.11. Impact of Lockdown in Their Life: The countrywide lockdown since March 25, 2020 to May 31, 2020 has a long term impact on these indigenous people i.e. Bhumij tribe in this village. As already stated, 15 migrant labours, having an original resident of this village, came back to their village from different states and they are now completely jobless. Not only those 15 migrant labours but this countrywide lockdown due to COVID-19 has also greatly affected the whole Bhumij people residing in this village. They cannot earn money from their different occupation for example who earn their daily wages from fishing in nearby Kangsabati river by selling fish, they sold their fishes with very low price as due to lockdown a negligible number of the local customer only took fishes from them, no outside customer could not reach their fishmarket due to lockdown. Besides that, who runs their livelihood on animal husbandry, they also faced the same crisis of low market price of their animal husbandry product like egg, animal, etc. In this context, one housewife engaged in animal husbandry, Rekha Kotal ( name changed due to protect her privacy), age of 37 years old said to us that she sold egg of chicken, goose and goat at half of the price with respect to the selling price before lockdown. She also sadly expressed that at present during this unlock phase 1.0, she cannot get proper market price of her product. She said to us if the government helps us by providing loan at reasonable subsidy for their animal husbandry then they can minimize their loss and can continue their life-battle through this their small profession. Sadhan Sing Sardar (name changed due to protect his privacy), the only graduate unmarried person of this village of 43 years old said to us that during lockdown period and after that they got rice, sugar, kerosene at completely free of cost from ration shop by the government of West Bengal but it does not full-fill their demand. They demand dal (pulses), mustered oil also at free of cost from ration shop otherwise they will remain hungry in very near future as their income from the various occupation is now at danger position. In addition to that he also very sadly said that in their nearby villages so many non-government organization (NGO) helped the villagers by providing cooked- foods, rice, potato, mustard oil, vegetables, soap, face-mask, etc. but in their village, no one comes so far.

\section{EPILOGUE}

The Bhumij tribes at Lutia village of Bankura district is a socially, economically and culturally diversified village in compare to the surrounding area. It has seen from the findings of this explorative study that the tribal dwellers of this village are deprived of basic necessities of life. India's schemes for affordable housing for the poor and access to sanitation, enjoyed by other towns and villages, still remain beyond their reach. Electricity has yet to be connected to their homes -only a bulb is lit- and they still live in mud-tiles, leaf, grass and mud made huts. Most of them are facing the problem of unemployment making their survival difficult. They could not maintain their livelihood due to their low incomes and no savings of money during this COVID-19 pandemic situation. The hostels for Tribal students of different schools nearby to this village have been stopped since 2019, as a result, tribal students not only from this village also from the adjacent area are now come back to their home by stopping their education, it is a serious tragedy in the field of school education of tribal students in this area. So they are stressed with education, economic and social backwardness and child sex ratio also.

\section{REFERENCES}

1. Risley, H.H. (1998). The Tribes \& Castes of Bengal, Vol. II. Calcutta: Firma KLM Pvt. Ltd.

2. Tripathy, C.B. (1971). The Tribal Life in India. New Delhi: National Book Trust.

3. Upadhyay, H. C. (1991). Scheduled Caste and Scheduled Tribes in India A SocioEconomic Profile. New Delhi: Anmol Publications.

4. Vidyarthi, L.P. \& Kumar, R.B. (2000). The Tribal Culture of India. New Delhi: Concept Publishing Company.

5. Reading Material for ASHA Book No.-1, issued by the Ministry of Health and Family Welfare, Govt. of India, Retrieved from https://nhm.gov.in/images/pdf/communitisati on/asha/book-no-1.pdf on June 30, 2020 at 11:54.

6. https://www.censusindia.co.in/villages/lutiapopulation-bankura-west-bengal-329151

7. http://www.scstrti.in/index.php?option $=$ com _content\&view $=$ article \&id $=153 \% 3 \mathrm{Abhumij}$ \#7s8d6f87 